Author(s):
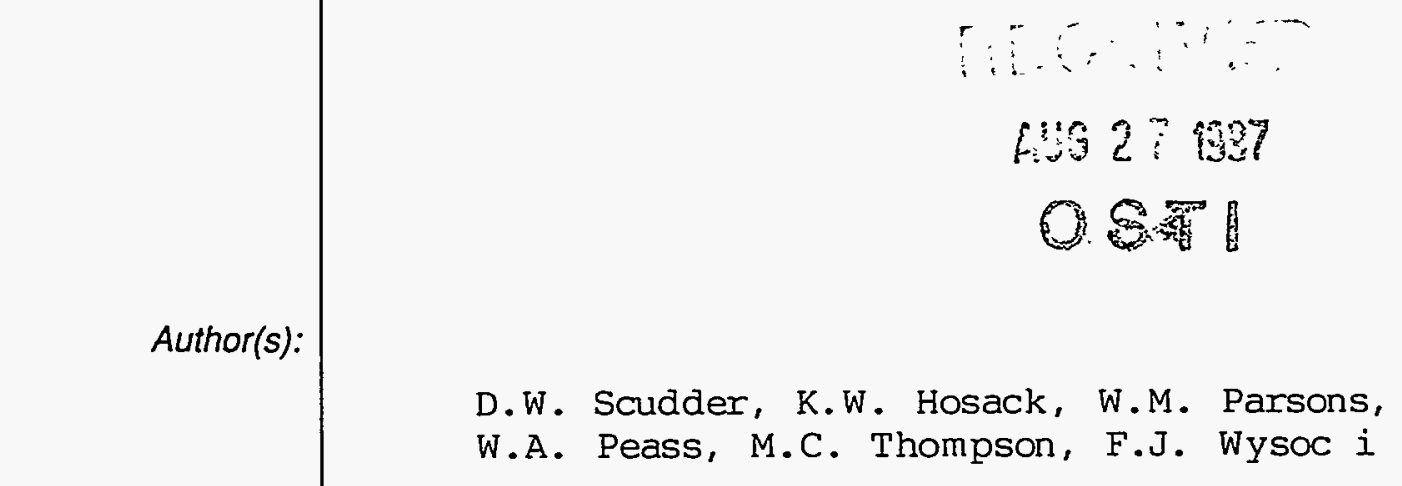

DISTRISUTION OF THE DOCUMENT IS UNLIMITED KJ
Submitted to:
IEEE Transactions on Plasma Science on
Pulsed Power Science and Technology

DISCLAIMER

This report was prepared as an account of work sponsored by an agency of the United States Government. Neither the United States Government nor any agency thereof, nor any of their employees, makes any warranty, express or implied, or assumes any legal liability or responsibility for the accuracy, completeness, or usefulness of any information, apparatus, product, or process disclosed, or represents that its use would not infringe privately owned rights. Reference herein to any specific commercial product, process, or service by trade name, trademark, manufacturer, or otherwise does not necessarily constitute or imply its endorsement, recommendation, or favoring by the United States Government or any agency thereof. The views and opinions of authors expressed herein do not necessarily state or reflect those of the United States Government or any agency thereof.
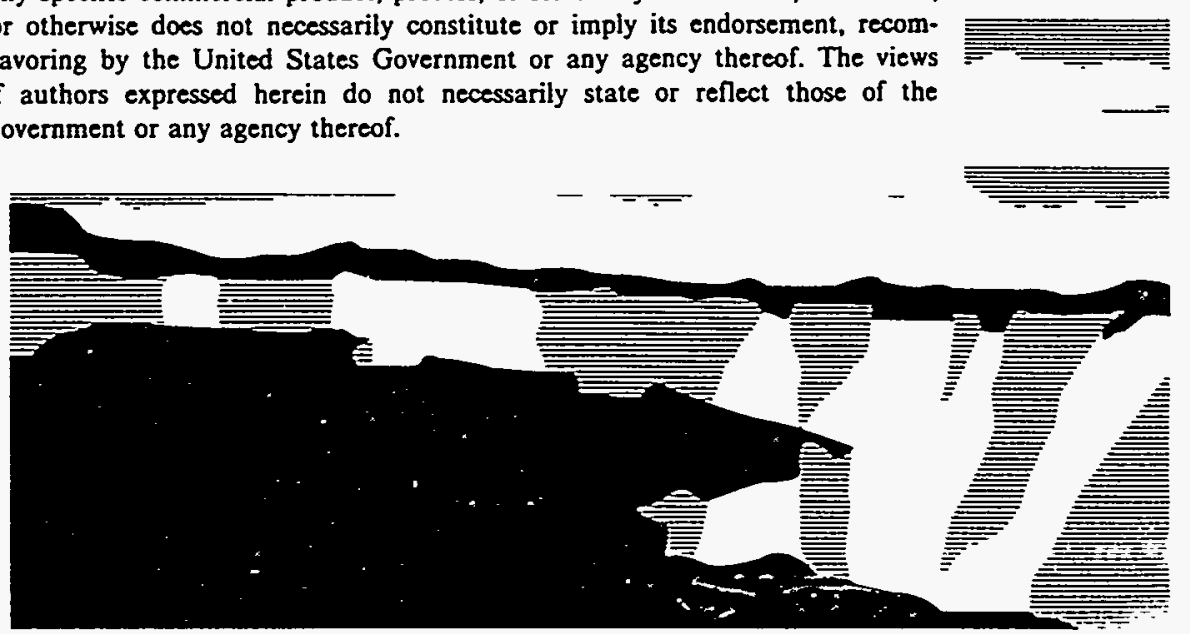


\section{DISCLAMMER}

Portions of this document may be illegible in electronic image products. Images are produced from the best available original document. 


\title{
CONTROLS AND DATA ACQUISITION ON ATLAS
}

\author{
D. W. Scudder, K. W. Hosack, W. M. Parsons, W. A. Reass, M. C. Thompson, F. J. \\ Wysocki,
}

Los Alamos National Laboratory, Los Alamos, New Mexico 87545

\author{
J. Creager
}

Allied Signal, Albuquerque, NM

\begin{abstract}
The control and data acquisition systems for Atlas will use a large degree of decentralization. By distributing control points close to the systems being controlled we expect to simplify the task of isolating electonic systems from the large expected EMI pulses, allow connection of the various parts of the system by high-level fiber-optic networks, allow a simple configuration of the control and data acquisition screen rooms, and simplify the software efforts through the resulting modularization. The Atlas control system must control capacitor charging, machine and diagnostic timing and triggering, marx module diagnostics, vacuum systems, gas handling for railgaps, safety interlocks, and oil handling. Many of these tasks will be performed by industrial-style programmable logic controllers (PLCs). Each of 38 Marx bank maintenance units will have a control and diagnostic package which will monitor both charging and discharging current and railgap trigger timing. An unusual feature of these marx monitoring stations will be the inclusion of high speed digitizers to record each marx module's output waveform, plus nanosecondresolution time interval meters to record the firing time of each railgap. The machine data acquisition system for Atlas will be built around an SQL database, use National Instruments LabVIEW software to control data acquisition instruments and provide links for a variety of experimentalists' data analysis packages. World Wide Web access will provide an interface through which users can monitor experimental data and machine status.
\end{abstract}

\section{System overview}

The Atlas machine at Los Alamos National Laboratory is a large, $36 \mathrm{MJ}$, capacitor bank being built to carry out hydrodynamic experiments as part of the Department of Energy's Science-Based Stockpile Stewardship program. The pulsed power systems and 
experimental program are described in other papers at this conference. This paper will describe the control and data acquisition systems for Atlas.

Several overal requirements have a significant impact on the control and data acquisition system designs. The need to operate in an environment of large electromagnetic pulses drives us to use fiber optics wherever possible for transimission of signals. This plus the desire to build a modular system drive us to locate control intelligence near to the equipment being controlled. Cost and the maturity of the controls market lead us to use commercial hardware and software wherever possible.

Figure1 provides a schematic overview of the system showing the several networks which will connect the various subsystems. These include networks to communicate with distributed programmable logic controllers (PLCs) (whose networks may be proprietary to the PLC vendor or may use ethernet), fiber-optic GPIB to talk to distributed data

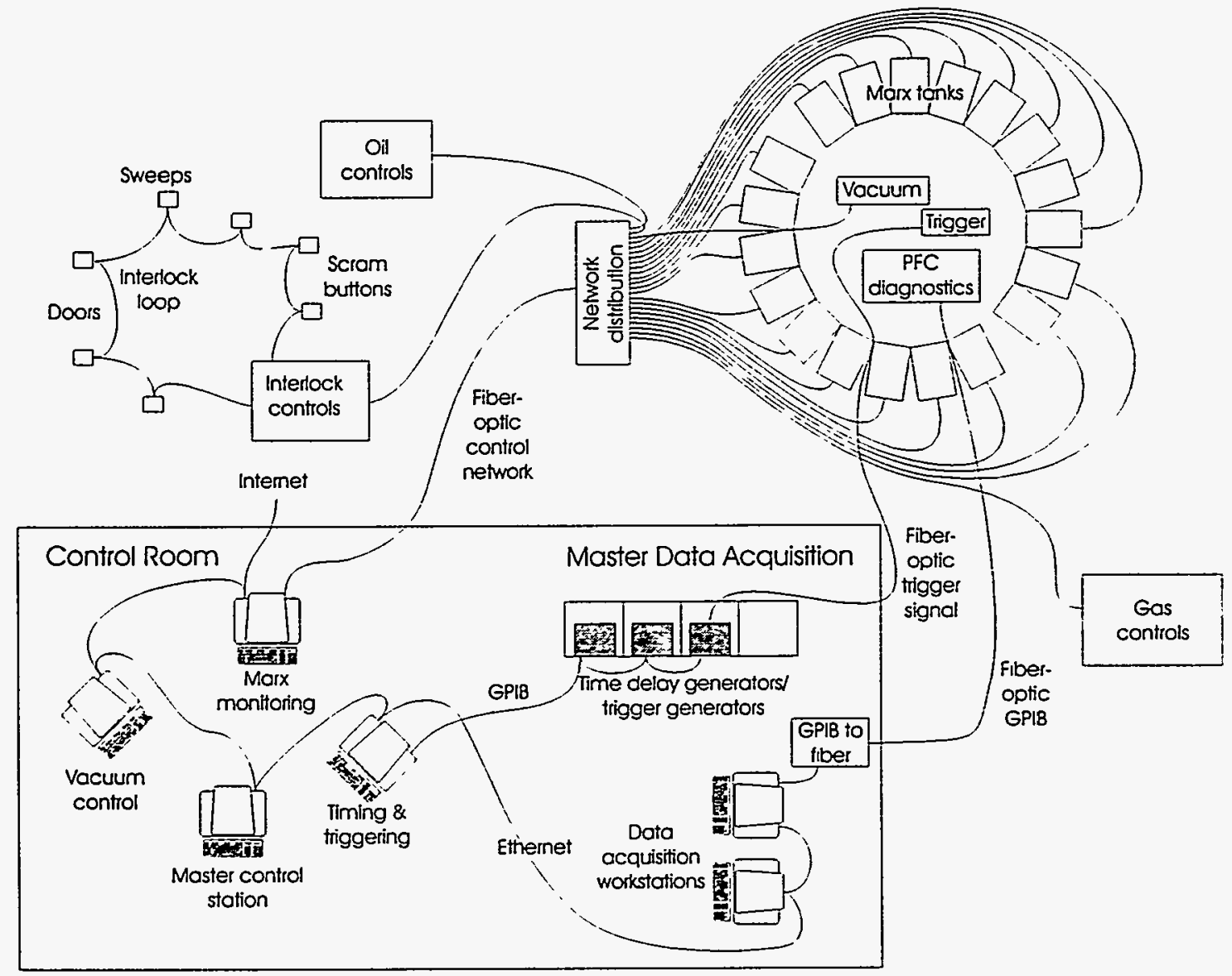

Figure 1. Control and data acquisition networks.

recording instruments, and ethernet connecting the control and data acquisition computers to the Los Alamos network and the Internet. Dedicated fiber links will carry time-critical signals such as marx bank triggering. 
This figure also illustrates that the Atlas control system will consist of a number of subsystems. These include:

- Master control

- Marx module charging, diagnostics, safing and local gas control

- Interlocks

- Timing and triggering

- Vacuum system control

- Oil transfer and filtering control

- Gas reclaimer and distribution control

- Master diagnostics

\section{Master control}

The master control system will communicate with the various subsystems, coordinate their operations, provide the operator interface (the vacuum system will also have a local console for operator instructions) and archive operation data with the database shared with the data acquisition system. This system will consist of several workstations, probably running the Windows NT operating system. The operator interface will use commercial human-machine interface software.

\section{Marx bank control system}

Most of the control operations on Atlas will involve local control boxes located as part of each of the Marx maintenance modules. A maintenance module consists of four Marx banks, with 38 maintenance modules making up the whole system (for a total of 152 Marx banks). The Marx control boxes will be called upon to carry out a wide variety of functions.

Figure 2 illustrates many of these functions. The power supplies to charge the Marx banks are expected to be distributed near the Marx modules, so the Marx control boxes will control the charging while monitoring for faults in the charge system. In addition, the control boxes will operate fast and slow dump switches, power supply disconnect switches, monitor bank voltage and charge current, control power and gas to trigger generators and control fill and flush valves on the railgaps (the main discharge switches for the Marxes).

A pair of fast diagnostics will be fielded in the Marx control boxes to monitor the discharge cycle of the Marxes. Analog-to-digital converters at $40 \mathrm{Msamples} / \mathrm{sec}$ will record the discharge waveform of each Marx bank during each shot from Rogowski coils on their outputs. In addition, time interval meters with sub-nanosecond resolution looking at the signals from $\mathrm{V}$-dot probes will measure the firing time of each railgap. In 


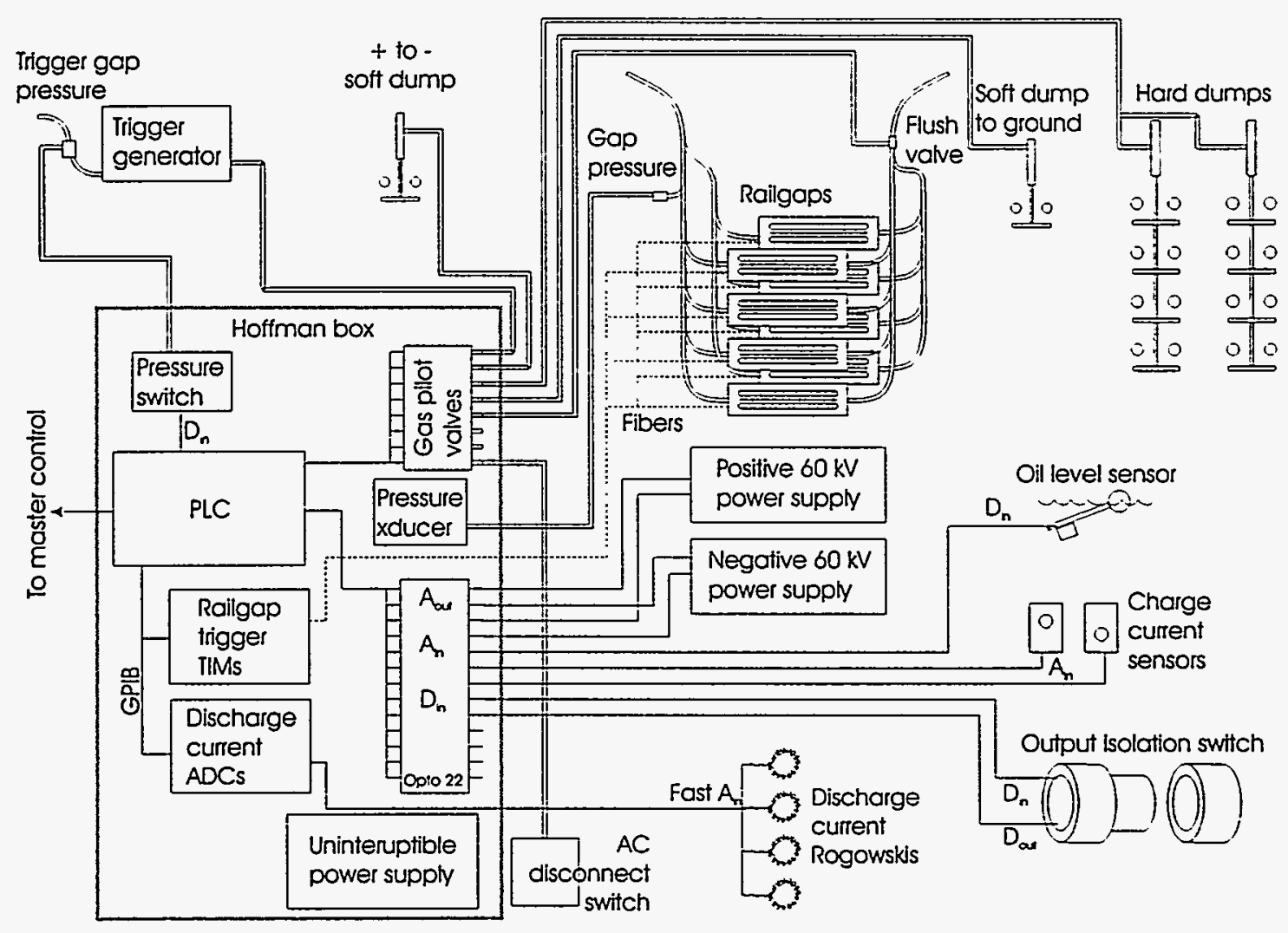

Figure 2. Marx module control box functions.

the case of railgap prefires, the V-dot signals will be available to initiate firing part or all of the rest of the railgaps, as is judged appropriate. These fast diagnostics will share the fiber-optic communication channel used by the PLC in the control box.

Each control box will provide a watchdog output to the interlock system, which will force a machine shutdown if the control box logic fails to update the watchdog.

\section{Interlock system}

Personnel safety from high voltage and various other hazards will be provided by access control coordinated by the interlock system. Door and panel sensors will detect any attempt to access areas containing hazards, and the interlock system will control means of disabling the hazards in those areas. In addtion to these sensors there will be scram switches distributed liberally throughout areas containing hazards. A sweep system will consist of switches distributed within exclusion areas and logic forcing an operator to walk through exclusion areas toggling the switches to assure that the areas are vacant before allowing hazardous systems to be enabled. Finally, watchdog signals from critical PLCs will force safing in the event of a control failure. 
This system will consist of completely redundant PLCs, sensors and outputs, so that a single point failure in the system cannot lead to a hazardous situation. All the locations monitored by the interlock system will be identifiable from either of the redundant

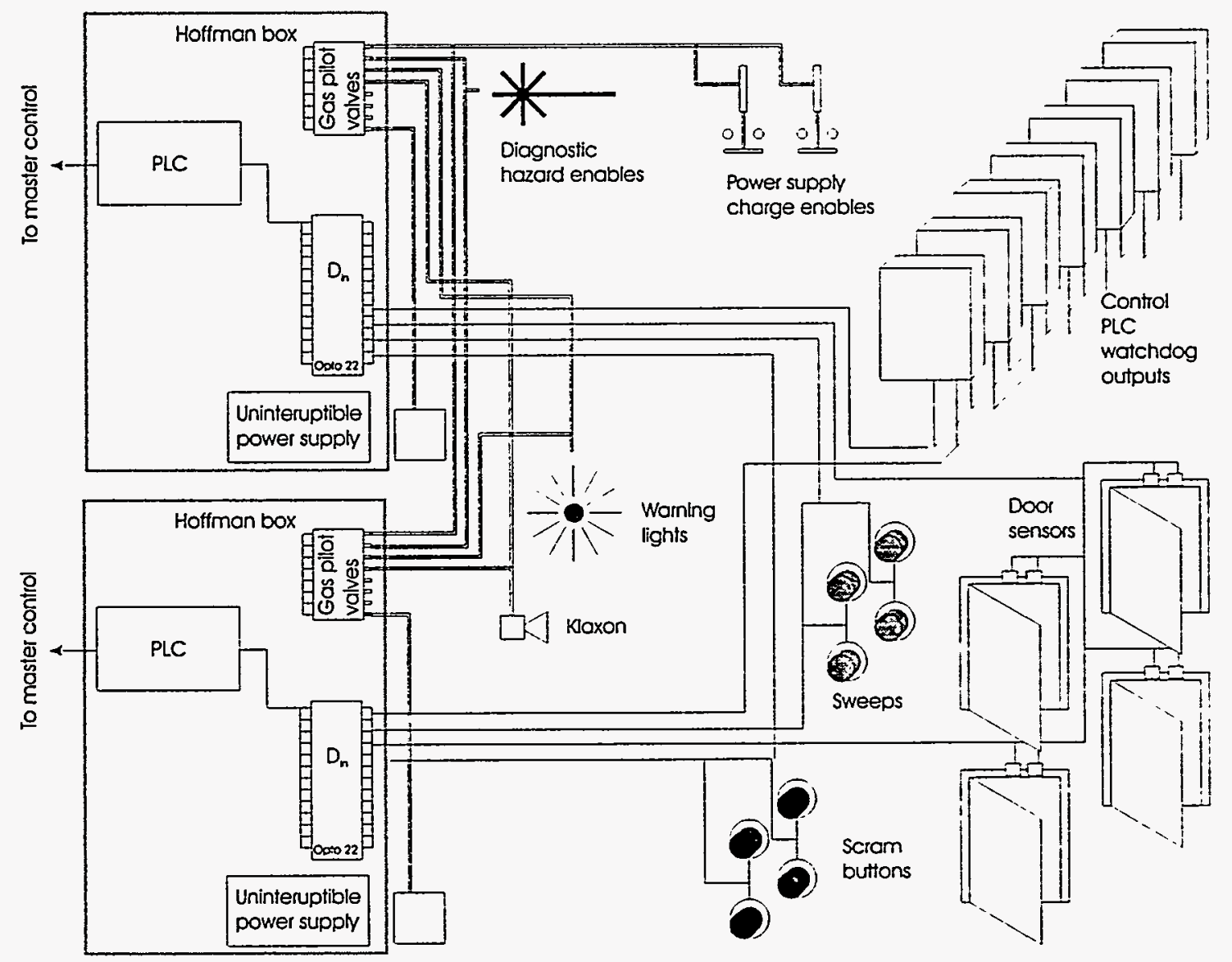

Figure 3. Interlock system showing redundant sensors and PLCs.

systems, so that any disagreement between the systems will identify and localize a system fault, i.e. the complete system will be self-diagnosing.

At least five different exclusion areas will be established for hazardous operations in different areas and under different machine operation modes. Since these will be defined in software, these areas can all be controlled by one (redundant) interlock system and reconfiguration will not require hardware changes.

\section{Triggering and timing}

Unlike the other control subsystems, the triggering and timing system will not use a PLC. Programmable delay generators will be controlled by the master control system, and the rest of the system will be hardwired. Signals leaving the screen room to fire the Marx 
bank triggering system and to trigger remote data acquisition systems will use high-speed analog fiber-optic links.

\section{Other subsystems}

The remaining control subsystems, vacuum, oil and gas, will use PLCs in conventional industrial control configurations.

\section{Master data acquisition system}

The master data acquisition system will acquire data from machine performance diagnostics, provide scalable support to users' diagnostics, and coordinate access to all the Atlas diagnostic data (user diagnostics and machine diagnostics).

Atlas machine diagnostics will consist of a number of current probes located near the center of the machine, including B-dot pickups, Rogowski loops, fiber-optic-based Faraday rotation diagnostics, and possibly voltage probes. The master data acquisition system will provide signal handling and recording channels for these diagnostics. Recorders are expected to be housed in small, roll-around, screened enclosures located near the signal sources and communicating to the main data acquisition screen room over, for instance, fiber-optic GPIB or ethernet. Individual Marx bank current histories will be collected by the control system and trasferred to this system after each shot.

The master data acquisition system should also provide recording channels to user diagnostics, if needed, and the ability to interface to a user's standalone data recording system if the user provides one. Users with standalone data acquisition will be required to make diagnostic data available to the master data acquisition system in a consistent form to be stored on the Atlas database server in a timely manner after a shot.

The Atlas database server will be a high-end database engine and will server as a repository for all Atlas unclassified experimental results, configuration data and machine operation parameter storage. The master control system will utilize the database to store its configuration and operation logs.

By storing all of the Atlas data in a single location, access to the data will be possible over a world-wide web server. The server will make diagnostic data available for graphing to a web browser and for download in any of a variety of common formats. 